\title{
Randomized controlled trial of ionization and photoelectric smoke alarm functionality
}

\author{
B A Mueller, ${ }^{1,2}$ E A Sidman, ${ }^{1,2}$ H Alter, ${ }^{1}$ R Perkins, ${ }^{3}$ D C Grossman ${ }^{1,4}$
}

${ }^{1}$ Harborview Injury Prevention and Research Center, Seattle, Washington, USA; ${ }^{2}$ Department of Epidemiology, School of Public Health and Community Medicine, University of Washington, Seattle, Washington, USA; ${ }^{3}$ Alaska Injury Prevention Center, Anchorage, Alaska, USA;

${ }^{4}$ Department of Health Services, School of Public Health and Community Medicine, and Department of Pediatrics, School of Medicine, University of Washington, Seattle, Washington, USA

Correspondence to:

Dr Beth Mueller, PO Box 19024, Mailstop M4-C308, Seattle, WA 98109-1024, USA; bmueller@ fhcrc.org

Accepted 27 November 2007

\section{ABSTRACT}

Objective: To compare functionality, reasons for nonfunction, and nuisance alarm levels of two common types of smoke alarms after installation in low- to mid-level income households in King County, Washington.

Methods: Randomized controlled trial of 761 households. An ionization or photoelectric smoke alarm was installed between June 1, 2000 and July 31, 2002. Main outcome measures were: percentage of study alarms that were working, observed reasons for non-functional status, and self-reported frequency of nuisance alarms at 9 and 15 months of follow-up.

Results: At 9 months after installation, $20 \%$ of ionization, vs $5 \%$ of photoelectric alarms were non-functional, a difference that persisted at 15 months, with the most common reasons for both types being a disconnected or absent battery. The risk ratio for ionization, relative to photoelectric alarms, being non-functional or removed was 2.7 (95\% Cl 1.8 to 4.1$)$ at 15 months of follow-up. These findings were not altered by educational level, or the presence of smokers, children $<5$ years, or adults $\geqslant 65$ years.

Conclusions: Burn prevention efforts are geared towards increasing smoke alarm ownership and improving maintenance of functional status. Results suggest that the selective use of photoelectric alarms by fire injury prevention programs or consumers may provide longerterm protection in similar populations. Designing smoke alarms that minimize nuisance alarming may also result in longer term functionality.

Smoke alarms are effective interventions for injuries from residential fires. ${ }^{12}$ Recent surveys indicate that $95-97 \%$ of US households have at least one smoke alarm, ${ }^{3}{ }^{4}$ with lower prevalence in rural areas. ${ }^{5}$ However, alarms disconnected from batteries, containing dead batteries, or removed due to nuisance alarms offer no protection. Inoperability levels range from $20 \%{ }^{67}$ to $36 \%{ }^{8}$

The most common types of alarms marketed for home use are ionization, photoelectric, and combination units. Photoelectric and ionization alarms operate via different mechanisms, detecting visible, and invisible/fine, byproducts of combustion, respectively. ${ }^{9}$ Photoelectric alarms use optical sensors and are more likely to sound due to slow, smoldering conditions. Ionization units are more responsive to flames by detecting charged particles from rapid combustion.

Nuisance alarms, often set off during cooking, are often cited as a reason why occupants disconnect alarms. ${ }^{81011}$ A study conducted in Alaskan villages reported that ionization alarms were more likely to nuisance alarm than were photoelectric alarms. ${ }^{11}$ However, a randomized trial of a smoke alarm distribution program in a poor neighborhood of London reported that photoelectric alarms were more likely to sound nuisance alarms. $^{12}$

We conducted a randomized controlled trial to compare the functionality of ionization and photoelectric smoke alarms by installing them in middleto low-income households in King County, Washington, and comparing their functional status, reasons for non-function, and frequency of nuisance alarms at 9 and 15 months of follow-up.

\section{METHODS}

\section{Participant identification}

A proprietary database of all private property in King County in 2000 (MetroScan) identified owner-occupied dwellings within the lower quartile of assessed values $(<\$ 164000)$ in census tracts with above-median density (755+ homes). This was to include homes at greatest risk of injury from residential fires, given the inverse association observed between socioeconomic status or income level and fire injury risk. ${ }^{13}{ }^{14}$ Condominiums were excluded, as the study's smoke alarm installation and placement protocols may conflict with those specified in condominium covenants. Selected residences were mailed a letter inviting participation in a "fire safety study" in cooperation with the King County Fire Chiefs' Association, involving installation of smoke alarms and provision of fire extinguishers. Homeowners were not informed of underlying hypotheses. Up to 10 phone calls and 2 messages were attempted to invite participation.

Only 58 participants enrolled after 4 months, an accrual rate that would have yielded insufficient participants. Thus, a "blockwalk" approach was initiated in which study staff visited households. From the pool of eligible dwellings, we identified clusters of potential participants using Thomas Guide map grids ${ }^{15}$ to maximize efficiency of identification. Twenty multi-day blockwalks to these areas were conducted, each targeting 200-800 potential residences. Within each blockwalk, households were randomly selected to receive either an ionization or photoelectric alarm. Ultimately, 6236 homes were identified for approach using this method (fig 1).

Staff worked in pairs during home visits during June 1, 2000 to July 31, 2002. If potential participants were at home, the team invited participation, either then or later. If nobody was at home, they left a letter indicating that a smoke alarm installation team would return on a future date. Residents could call to refuse, schedule an appointment, or be visited on the return date. 


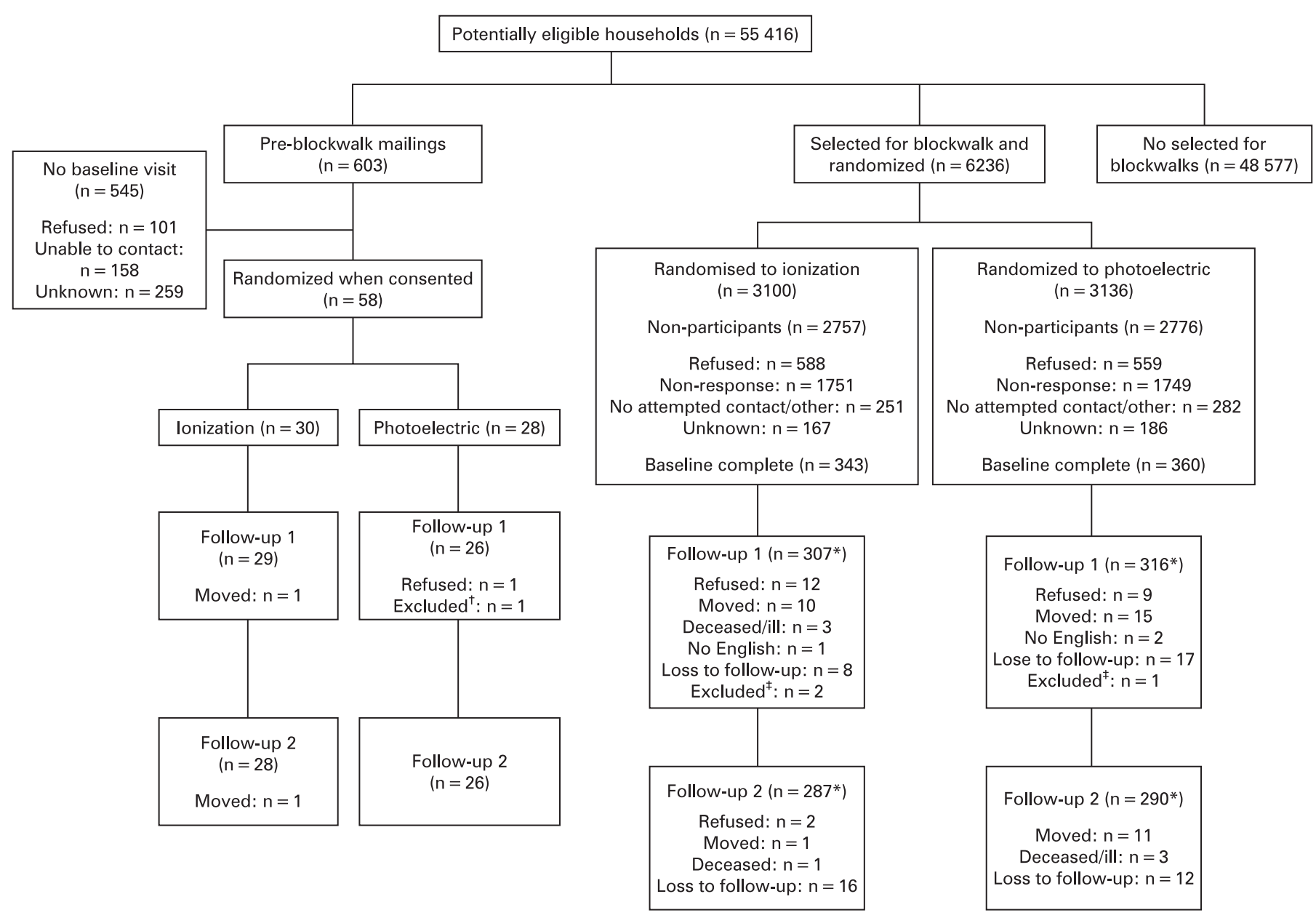

Figure 1 Flow of households through the trial. *Four homes in ionization and two in photoelectric study groups excluded from follow-up analyses because original zinc batteries replaced with alkaline batteries. $\uparrow$ Study smoke alarm never installed. $\dagger$ Renters.

Procedures were approved by the Human Subjects Division at the University of Washington prior to study conduct.

\section{Baseline visits}

A standardized survey was conducted, followed by installation of one study alarm per household. The survey queried demographics, fire safety practices and behaviors, history of fire or related injuries, building characteristics, heating and cooking fuel sources, sources of fires, flames, or smoke, and presence and locations of existing smoke alarms. A "target" date was set for the first 9-month follow-up. No appointment time was arranged, to keep subsequent inspections unannounced and decrease the likelihood of observing behavior altered by anticipation of a repeat visit.

Study personnel were trained in smoke alarm installation as described by the US Fire Administration ${ }^{16}$ using the National Fire Alarm Code Handbook. ${ }^{17}$ Participants were not informed of hypotheses or type of alarm installed, although they were informed they would receive an alarm endorsed by the National Fire Protection Agency (NFPA) for residential use. Because of the different appearance of the two alarms, it was not possible to blind study staff to alarm type; however, staff were not informed of underlying hypotheses. Teams were asked to install study alarms on main levels, in rooms adjacent to kitchens. Adjacent rooms without alarms were the highest priority in selecting the location. Alarms were mounted on the wall 3 feet from the kitchen entrance and 4-12 inches from the ceiling, a location with potentially greater chance of having nuisance alarms. If alarms were already installed in that room, the study alarm would be installed in the same room; however, the installer would re-install the existing alarms elsewhere if requested. Both alarm units had "hush buttons" and zinc batteries, which were tested and installed with the alarm. Original batteries were marked with indelible ink to later determine whether new batteries had been installed. The alarm's baseline function was tested with canned smoke, and participants instructed in alarm maintenance. The operation manual and a fire safety brochure were provided. Residents were also given a fire extinguisher, instruction in its use, and information regarding optimal location.

At baseline, 761 homeowners were interviewed. Three were later found ineligible because they rented; 1 elected to have no alarm installed. The 757 remaining households included 371 randomized to receive ionization and 386 randomized to receive photoelectric study alarms.

\section{Follow-up visits}

At both follow-ups, we queried the status of all smoke alarms, occurrence of any fires and related alarms, and occurrence of nuisance alarms (ascertained separately for study and existing alarms) and their perceived causes. If alarms were reported nonfunctional, the reasons were asked. Teams inspected and tested study alarms to determine functionality, noted reasons for nonfunction, and observed battery status. If batteries were 
Table 1 Characteristics of respondents, households, and houses reported at baseline interview, by randomized study alarm type

\begin{tabular}{|c|c|c|}
\hline Characteristic & $\begin{array}{l}\text { Ionization } \\
\left(\mathrm{n}=366^{*}\right)\end{array}$ & $\begin{array}{l}\text { Photoelectric } \\
\left(\mathrm{n}=384^{*}\right)(\%)\end{array}$ \\
\hline \multicolumn{3}{|l|}{ Respondent } \\
\hline Female & 64.7 & 63.5 \\
\hline \multicolumn{3}{|l|}{ Age (years) } \\
\hline$\leqslant 24$ & 2.6 & 2.3 \\
\hline $25-44$ & 42.5 & 38.3 \\
\hline $45-64$ & 31.9 & 40.3 \\
\hline$\geqslant 65$ & 23.1 & 19.2 \\
\hline \multicolumn{3}{|l|}{ Race/ethnicity } \\
\hline White & 78.2 & 76.2 \\
\hline Asian/Pacific Islander & 10.7 & 11.4 \\
\hline African-American & 3.6 & 5.0 \\
\hline Hispanic & 3.0 & 3.2 \\
\hline Native American & 0.8 & 1.3 \\
\hline Multiracial & 3.0 & 1.3 \\
\hline Other & 0.6 & 1.6 \\
\hline \multicolumn{3}{|l|}{ Education } \\
\hline$<$ High school & 5.2 & 8.7 \\
\hline High school/GED & 21.2 & 25.2 \\
\hline Vocational/technical/some college & 30.0 & 30.5 \\
\hline$\geqslant$ College & 43.7 & 35.7 \\
\hline \multicolumn{3}{|l|}{ Household } \\
\hline \multicolumn{3}{|l|}{ Number of residents } \\
\hline 1 & 20.5 & 19.0 \\
\hline 2 & 32.5 & 31.5 \\
\hline $3-4$ & 36.9 & 35.7 \\
\hline$\geqslant 5$ & 10.1 & 13.8 \\
\hline \multicolumn{3}{|l|}{$\geqslant 1$ resident aged } \\
\hline$\leqslant 4$ years & 16.2 & 15.7 \\
\hline$\leqslant 14$ years & 33.8 & 35.3 \\
\hline$\geqslant 65$ years & 29.0 & 25.5 \\
\hline$\geqslant 1$ resident smokes $\uparrow$ & 24.4 & 25.0 \\
\hline$\geqslant 1$ resident drinks alcohol & 25.9 & 25.3 \\
\hline \multicolumn{3}{|l|}{ House } \\
\hline Single family residence & 98.9 & 100.0 \\
\hline \multicolumn{3}{|l|}{ Year built } \\
\hline$\leqslant 1920$ & 9.1 & 11.2 \\
\hline $1921-1940$ & 17.8 & 15.2 \\
\hline $1941-1960$ & 42.7 & 41.3 \\
\hline $1961-1980$ & 22.5 & 21.2 \\
\hline 1981-1996 & 7.9 & 11.2 \\
\hline Ever structurally remodeled & 51.0 & 52.7 \\
\hline \multicolumn{3}{|l|}{ Year built or last remodeled } \\
\hline$\leqslant 1940$ & 9.2 & 7.4 \\
\hline $1941-1960$ & 27.4 & 22.9 \\
\hline $1961-1980$ & 28.4 & 26.3 \\
\hline $1981-2001$ & 35.0 & 43.3 \\
\hline \multicolumn{3}{|l|}{ Number of floors } \\
\hline 1 & 39.9 & 40.1 \\
\hline 2 & 47.3 & 48.7 \\
\hline$\geqslant 3$ & 12.8 & 11.2 \\
\hline \multicolumn{3}{|l|}{ Years in current house } \\
\hline$<1$ & 6.6 & 4.2 \\
\hline $1-5$ & 31.7 & 29.0 \\
\hline $6-10$ & 16.9 & 21.9 \\
\hline$\geqslant 11$ & 44.8 & 44.9 \\
\hline \multicolumn{3}{|l|}{ Kitchen stove type§ } \\
\hline Electric & 89.6 & 90.6 \\
\hline Gas & 10.7 & 9.4 \\
\hline \multicolumn{3}{|l|}{ Frequency of kitchen stove use } \\
\hline Daily & 64.5 & 66.6 \\
\hline Multiple days per week & 27.2 & 24.5 \\
\hline
\end{tabular}

Table 1 Continued

\begin{tabular}{lcc}
\hline Characteristic & $\begin{array}{l}\text { lonization } \\
\left(\mathbf{n}=\mathbf{3 6 6}^{*}\right)\end{array}$ & $\begin{array}{l}\text { Photoelectric } \\
(\mathbf{n}=\mathbf{3 8 4} \boldsymbol{*})(\%)\end{array}$ \\
\hline$\quad$ Rarely/occasionally/weekends only & 8.3 & 9.0 \\
Main heat source & & \\
$\quad$ Electric & 24.9 & 31.8 \\
$\quad$ Natural gas & 54.4 & 49.2 \\
Oil & 18.8 & 17.4 \\
Wood & 1.7 & 1.3 \\
$\quad$ Other & 0.3 & 0.3 \\
Electric main or secondary heat source & 33.6 & 40.6 \\
Natural gas main or secondary heat source & 53.5 & 49.3 \\
Oil main or secondary heat source & 19.0 & 18.5 \\
Open-element space heater & 19.5 & 20.8 \\
Wood fireplace & 37.5 & 47.1 \\
Gas fireplace insert & 4.9 & 1.8 \\
Wood or pellet stove & 20.8 & 20.8 \\
Frequency of fireplace or stove use & & \\
$\quad$ Daily/weekly & 39.1 & 30.2 \\
$\quad$ Bi-monthly/monthly & 12.1 & 14.3 \\
$\quad$ Rarely/never & 48.8 & 55.5
\end{tabular}

*Among households that were eligible for analyses (had study alarm installed, were home owners, and received a zinc battery in the study alarm).

†Defined as smoking a pack (20 cigarettes) or more per week.

Defined as drinking 5 or more alcoholic beverages on occasion

$\S$ Not mutually exclusive since some kitchens have two stoves, so percentages may add to $>100 \%$

- Based on the single most frequently used fireplace or stove per household.

inoperable, new alkaline batteries were installed. A $\$ 10$ reimbursement was provided per visit.

First follow-ups were completed with 336 (91\%) ionization and $342(89 \%)$ photoelectric study group homes. Mean (SD) elapsed times between baseline and first follow-ups were 9.0 (0.6) months (range 8.4-12.8) and 9.0 (0.6) months (range 8.413.4) for ionization and photoelectric alarms, respectively.

Second visits were completed for 315 ( $85 \%$ of baseline) homes randomized to the ionization and $316(82 \%)$ to the photoelectric group. Mean (SD) elapsed times between baseline and second follow-ups were 14.9 (0.7) months (range 14.0-18.9) for the ionization group, and 14.9 (0.8) months (range 14.1-19.0) for the photoelectric group. Reasons for exclusion were similar across study groups at both follow-ups.

\section{Data analysis}

Five households randomized to receive ionization alarms and 17 randomized to receive photoelectric alarms instead received the opposite type. Data were analyzed using an intention-to-treat approach in which participating households were categorized by alarm type to which they were randomized. For 5 ionization and 2 photoelectric study households, original batteries were inoperable, and new alkaline batteries installed. These were excluded from analyses. Although main analyses included all eligible households recruited, a sensitivity analysis was conducted using only the 700 eligible households recruited using the blockwalk method, yielding comparable results.

Baseline respondent and household demographics, structural and heating characteristics, safety practices, fire histories, and alarm installation locations were compared between study groups. Pearson's $\chi^{2}$ and Fisher's exact tests were used to compare groups with respect to frequency of household nuisance alarming and fire incidence between baseline and first follow-up, and between first and second follow-up (overall and after excluding households with inoperable alarms due to battery or alarm removal, or with otherwise malfunctioning 
alarms at first follow-up). The functional status of study alarms at each visit was compared. Associations between alarm type and non-functional or removed status at follow-up were estimated with cumulative incidence risk ratios (RR) and 95\% CIs. Effect-modification by respondent and household characteristics was explored using stratified analyses and the Mantel-Haenszel test for homogeneity. Generalized linear models specifying the binomial family and log link, appropriate for cohort studies of common binary outcomes, were used to adjust simultaneously for combinations of respondent and household characteristics. ${ }^{18}$ The presence of confounding was evaluated by the magnitude of change in RRs after adjustment for relevant factors, alone and in combination. No appreciable changes were noted after adjustment for potential confounders; unadjusted RRs are presented.

The majority of study variables were missing few values ( 0 $2 \%$ ). Exceptions included the years homes were built or remodeled, secondary heating sources, household testing of fire safety devices, and fire history. Participating households with missing values were dropped from analyses requiring the specific missing variable(s).

\section{RESULTS}

Nearly all alarms (99\%) were installed on main floors, with $65 \%$ in both ionization and photoelectric groups installed in hallways, dining rooms, or living rooms adjacent to kitchens. Study alarms were installed in kitchens for $20 \%$ of residences randomized to receive ionization alarms and $16 \%$ of those with photoelectric alarms; $16 \%$ and 18\%, respectively, were installed elsewhere. Similar proportions of ionization (88\%) and photoelectric $(90 \%)$ alarms were installed on walls, the remainder on ceilings. The mean (SD) distances between alarm locations and kitchen stoves were similar, at 136.0 (44.1) and 137.8 (47.2) inches.

Respondent, household, and house characteristics were similar for both groups, including the proportions of smokers and use of kitchen stoves and fireplaces, with a few exceptions (table 1). A slightly greater proportion of respondents with ionization alarms had college degrees (44\%) than those with photoelectric alarms (36\%). Homes receiving ionization alarms were slightly less likely to have been built or remodeled after 1980 (35\% vs 43\% of homes with photoelectric alarms), and have electrical heating as their main heat source (25\% vs 32\%), or wood-burning fireplaces (38\% vs $47 \%$ ). Homes with ionization alarms were slightly more likely to report natural gas as their main heating source (54\% vs $49 \%$ ), or have gas fireplace inserts ( $5 \%$ vs $2 \%$ ).

The self-reported number of smoke alarms already present, presence of fire safety equipment, and residential fire history were similar across groups (table 2). Photoelectric study group households reporting a prior residential fire were slightly more likely to have had fire-related injuries among residents (9\%) than were those within the ionization group (6\%).

Nuisance alarms by non-study alarms between baseline and first follow-up visits were similarly common among homes with ionization (43\%) and photoelectric (45\%) study alarms (table 3). Ionization units, however, reportedly were more likely than photoelectric units to have alarmed (78\% vs $39 \%, p<0.001)$, and alarmed more often $(56 \%$ vs $17 \%$ had $>3$ alarm episodes, $\mathrm{p}<0.001)$. Similar differences were observed for the interval between first and second follow-ups. On direct observation at first follow-up, ionization study alarms were more likely to be non-functional $(20 \%$ vs $5 \%$ photoelectric, $p<0.001)$, with the most common reasons being a disconnected ( $6 \%$ ionization vs $1 \%$ photoelectric, $\mathrm{p}<0.001)$, or absent battery $(13 \%$ ionization
Table 2 Reported use of fire safety interventions and fire history at baseline visit in study households, by alarm type

\begin{tabular}{|c|c|c|}
\hline Characteristic & $\begin{array}{l}\text { Ionization } \\
(\mathrm{n}=366)(\%)\end{array}$ & $\begin{array}{l}\text { Photoelectric } \\
(\mathrm{n}=384)(\%)\end{array}$ \\
\hline \multicolumn{3}{|l|}{ Safety practice } \\
\hline \multicolumn{3}{|l|}{ No. of smoke alarms present ${ }^{*}$} \\
\hline 0 & 9.3 & 9.9 \\
\hline 1 & 40.2 & 35.9 \\
\hline 2 & 29.2 & 33.6 \\
\hline$\geqslant 3$ & 21.3 & 20.6 \\
\hline \multicolumn{3}{|l|}{ Smoke alarm tested within past $\dagger$} \\
\hline 0-6 months & 77.0 & 73.9 \\
\hline $6-12$ months & 14.2 & 14.4 \\
\hline$>12$ months & 5.7 & 6.4 \\
\hline Never & 3.2 & 5.2 \\
\hline$\geqslant 1$ carbon monoxide alarm & 20.3 & 21.0 \\
\hline \multicolumn{3}{|l|}{ Carbon monoxide alarm tested within past $\dagger$} \\
\hline 0-6 months & 48.5 & 50.7 \\
\hline 6-12 months & 27.3 & 14.5 \\
\hline$>12$ months & 6.1 & 10.1 \\
\hline Never & 18.2 & 24.6 \\
\hline$\geqslant 1$ fire laddert & 7.8 & 5.8 \\
\hline$\geqslant 1$ fire extinguisher & 67.5 & 67.4 \\
\hline $\begin{array}{l}\text { Extinguisher pressure check within past } \\
9 \text { months§ }\end{array}$ & 31.1 & 32.4 \\
\hline Designated meeting location & 31.7 & 34.6 \\
\hline Know water temperature & 47.0 & 44.0 \\
\hline Water temperature $<120^{\circ} \mathrm{F}^{* *}$ & 64.9 & 66.7 \\
\hline \multicolumn{3}{|l|}{ Fire history } \\
\hline Prior fire & 11.0 & 10.5 \\
\hline Fire-related injuries $\dagger \dagger$ & 5.9 & 8.8 \\
\hline \multicolumn{3}{|l|}{ Prior fire } \\
\hline Never & 89.0 & 89.5 \\
\hline Fire without injuries & 9.0 & 8.4 \\
\hline Fire with injuries & 0.6 & 0.8 \\
\hline Fire with unknown injuries & 1.4 & 1.4 \\
\hline
\end{tabular}

*Not including study alarm.

$\uparrow$ Restricted to households self-reporting at least one such alarm.

tRestricted to houses of more than one floor.

§Restricted to households self-reporting at least one fire extinguisher.

- Restricted to households with more than one resident at some point during the

9 months prior to interview.

${ }^{*}$ Restricted to respondents who knew water temperature.

$\dagger$ Restricted to households self-reporting prior fire.

vs $1 \%$ photoelectric, $\mathrm{p}<0.001)$. These differences persisted at second follow-up. Ionization alarms were not, however, more likely to have been removed than were photoelectric alarms.

The RR associated with having an ionization study alarm, relative to a photoelectric alarm, be non-functional or removed at first follow-up was 3.8 (95\% CI 2.3 to 6.3), and 2.7 (95\% CI 1.8 to 4.1 ) at second follow-up (data not shown). When analyses for second follow-up were restricted to homes with alarms observed to be functional at first follow-up, the RR was 2.1 (95\% CI 1.2 to 3.5). The RR associated with having a disconnected or absent battery or removed alarm observed among ionization study alarms, relative to photoelectric alarms, was 5.3 (95\% CI 2.9 to 9.6) at first follow-up and 3.2 (95\% CI 2.0 to 5.1$)$ at second follow-up. Restriction of second follow-up analyses to homes with functional alarms at first follow-up resulted in an RR of 2.6 (95\% CI 1.4 to 4.7$)$. Stratification by respondent gender, race/ethnicity, education, number of occupants, presence of children, the elderly, smokers, or alcohol consumers, did not alter these results.

The most commonly reported reasons for nuisance alarms during the 15 month follow-up were cooking (93\% nuisance 
Table 3 Follow-up status of study smoke alarms, by follow-up visit and alarm type

\begin{tabular}{|c|c|c|c|c|c|c|c|c|c|}
\hline \multirow[b]{2}{*}{ Characteristic } & \multicolumn{3}{|l|}{ Follow-up 1} & \multicolumn{3}{|l|}{ Follow-up 2} & \multicolumn{3}{|l|}{ Follow-up 2* } \\
\hline & $\begin{array}{l}\text { Ionization } \\
(\mathrm{n}=332)(\%)\end{array}$ & $\begin{array}{l}\text { Photoelectric } \\
(\mathrm{n}=340)(\%)\end{array}$ & p-value $\dagger$ & $\begin{array}{l}\text { Ionization } \\
(\mathrm{n}=\mathbf{3 1 1})(\%)\end{array}$ & $\begin{array}{l}\text { Photoelectric } \\
(\mathrm{n}=314)(\%)\end{array}$ & p-value $\dagger$ & $\begin{array}{l}\text { Ionization } \\
(\mathrm{n}=248)(\%)\end{array}$ & $\begin{array}{l}\text { Photoelectric } \\
(\mathrm{n}=296)(\%)\end{array}$ & p-value $\dagger$ \\
\hline \multicolumn{10}{|l|}{$\begin{array}{l}\text { Participant-reported status } \\
\text { since last visit }\end{array}$} \\
\hline Fire & 2.4 & 2.4 & 0.97 & 1.6 & 2.6 & 0.41 & 0.8 & 2.4 & 0.19 \\
\hline Study alarm sounded & 77.9 & 38.7 & $<0.001$ & 76.8 & 42.0 & $<0.001$ & 74.2 & 41.8 & $<0.001$ \\
\hline $\begin{array}{l}\text { No. of times study alarm } \\
\text { sounded } t\end{array}$ & & & $<0.001$ & & & $<0.001$ & & & $<0.001$ \\
\hline $4-10$ & 26.6 & 11.0 & & 27.7 & 11.0 & & 21.7 & 9.2 & \\
\hline$\geqslant 11$ & 29.4 & 5.5 & & 16.0 & 0.8 & & 16.9 & 0.8 & \\
\hline Other alarm(s) sounded§ & 42.5 & 45.4 & 0.49 & 33.0 & 37.6 & 0.26 & 30.2 & 36.7 & 0.14 \\
\hline $\begin{array}{l}\text { No. of times other alarm(s) } \\
\text { sounded } \$\end{array}$ & & & 0.89 & & & 0.28 & & & 0.07 \\
\hline $1-3$ & 73.0 & 72.5 & & 65.5 & 73.0 & & 60.9 & 73.1 & \\
\hline Functional & 79.6 & 94.7 & $<0.001$ & 76.8 & 91.4 & $<0.001$ & 85.8 & 93.2 & 0.004 \\
\hline \multicolumn{10}{|l|}{ Non-functional due to } \\
\hline Malfunctioning alarm & 0.3 & 0.0 & 0.49 & 0.3 & 0.3 & 1.00 & 0.4 & 0.3 & 1.00 \\
\hline Disconnected battery & 5.8 & 0.6 & $<0.001$ & 5.5 & 1.3 & 0.004 & 4.1 & 0.7 & 0.008 \\
\hline Absent battery & 12.8 & 1.2 & $<0.001$ & 14.5 & 2.2 & $<0.001$ & 7.7 & 2.4 & 0.004 \\
\hline Dead battery & 0.9 & 1.5 & 0.73 & 1.3 & 1.3 & 1.00 & 1.6 & 1.4 & 1.00 \\
\hline Incorrect battery placement & 0.0 & 0.0 & - & 0.0 & 0.3 & 1.00 & 0.0 & 0.3 & 1.00 \\
\hline Unknown & 0.3 & 0.3 & 1.00 & 0.3 & 0.0 & 0.50 & 0.0 & 0.0 & - \\
\hline Study alarm removed & 0.3 & 1.8 & 0.12 & 1.3 & 3.2 & 0.11 & 0.4 & 1.7 & 0.23 \\
\hline
\end{tabular}

* Restricted to households with functional study alarms at follow-up 1.

$\uparrow$ Based on Pearson's $\chi^{2}$ test if expected $\geqslant 5$ in all cells; based on Fisher's exact test if expected $<5$ in any cell.

Restricted to households whose smoke alarm(s) had alarmed since the last visit.

$\S$ Restricted to households with reported non-study alarms at baseline.

alarms in ionization group, $74 \%$ in photoelectric group), low batteries ( $5 \%$ and $22 \%$, respectively), fireplaces ( $2 \%$ both groups), and steam ( $1 \%$ ionization, $2 \%$ photoelectric). Smoking was reported as a source of nuisance alarms only among $1 \%$ in the photoelectric group. Other reasons for nuisance alarming of study detectors were incense $(<1 \%$ ionization group), candles ( $1 \%$ both groups), construction $(<1 \%$ ionization, $2 \%$ photoelectric), and heat from lights $(2 \%$ ionization group).

\section{DISCUSSION}

Compared to ionization alarms, photoelectric alarms were more likely to be functional both 9 and 15 months after installation, and had fewer absent or disconnected batteries. The greater proportion of functioning photoelectric alarms may be attributable to fewer nuisance alarms. Thus, photoelectric alarms may be preferred when a single unit is selected by consumers or safety campaigns targeting similar populations, particularly when the alarm is installed adjacent to a cooking area as in our study.

These findings are consistent with previous work conducted by this center. Among smaller residences in rural Alaskan Native villages, eight times as many nuisance alarms by ionization units were reported, compared to photoelectric units, after 6 months of follow-up. Ionization alarms were also more likely to be disabled or missing batteries. ${ }^{11}$

Our findings differ from those of another trial conducted among residents of low-income housing units in London, in which ionization alarms were more likely than photoelectric alarms to be functional 15 months after installation. ${ }^{12}$ The proportions of functional alarms among both groups (47\% ionization vs $36 \%$ photoelectric) were considerably lower at follow-up than what we observed (77\% ionization, $91 \%$ photoelectric). The difference in proportions of homes with alarms present at baseline (11\% London vs $90 \%$ our study) suggests wide differences in population characteristics, and emphasizes the importance of appropriately designed injury prevention strategies. Smoke alarms are less common in rented than owner-occupied dwellings, ${ }^{19}$ which may account for some of the difference. Although the London and Seattle-area study households contained similar proportions of young and elderly occupants, smokers resided in nearly $50 \%$ of the London homes versus $24 \%$ in our study. If cigarette smoking is more likely to cause nuisance alarming by photoelectric units (which respond more quickly to smoldering fires), this difference in households with smokers may be partly responsible. Differences in cooking styles, heating sources, ventilation, or use of wood-burning fireplaces may also have accounted for variation in air particulates emitted, and resulted in differing false alarm patterns. Homes in our study, all single family residences, were likely larger than in the UK study, potentially affecting the concentration and circulation of air particulates, and relative potential for nuisance alarms by detector type. Finally, although both studies targeted lower income groups, our participants were likely of relatively greater socioeconomic status, given that home ownership was required for eligibility.

Because of the poor long-term functional prognosis for either alarm type in the London study, the authors concluded that 
sprinkler systems may provide the most efficient use of limited government resources in that environment. This contrasts with some studies in other environments, where smoke alarm installation programs appear effective. ${ }^{20}$

\section{Limitations}

Although study staff directly observed functional status of the smoke alarms and reasons for non-function, the occurrence and reasons for nuisance alarms were participant-reported. Another potential limitation involved the method used to recruit households. Because of low success using targeted mail invitation, we switched to blockwalk recruitment targeting high density areas and recruited people at home, given that mail response is generally lower than in-person contact. ${ }^{21}$ We attempted to reduce potential bias associated with nonresponse by leaving letters if occupants were absent, and attempting re-contact. Nonetheless, some potentially eligible homes could not be reached. The impact of this is unclear, but we doubt differential bias because proportions consenting and reasons for non-participation were similar between study groups. We are also reassured that the proportion of enrolled homes with existing smoke alarms is similar to that in surveys from the same time. ${ }^{22}$ Potential biases may have been introduced in using two different recruitment methods, although there is evidence of no significant differences in subjects identified by mailing and home visit. ${ }^{23}$ We also obtained no information about presence or use of fans over cooking surfaces. Our results are based on single family, owner-occupied households, and it is possible that household characteristics may vary between those in the study and those of rental units or condominiums. Finally, it should be noted that although we installed alarms in the room adjacent to the kitchen, current recommendations are that alarms be installed on every level of a home, in particular, outside every sleeping area. ${ }^{24}$

\section{Implications for prevention}

Improving functional status of smoke alarms is important. Even after installing alarms at no cost to homeowners, 10-25\% were non-functional at follow-up. Battery removal by residents was the most common reason for non-functional alarms, with cooking most commonly identified as the reason for nuisance alarms. Although lithium batteries may reduce the prevalence of non-functional alarms from dead batteries, they do not address the issue of frequent nuisance alarms, which homeowners appear unwilling to tolerate. Design improvements to reduce false alarms may help to reduce disarming by residents.

A recent survey of US department and home improvement stores shows that battery operated ionization devices are available for $\$ 10$ (US), photoelectric devices for $\$ 15$, and dual sensor units for approximately $\$ 25$. Some manufacturers recommend that consumers install both ionization and photoelectric alarms, or use hybrid units. The US Consumer Product Safety Commission and NFPA guidelines describe both technologies in their instructional materials, but currently do not recommend use of one over the other. The NFPA guidelines state that since "you can not predict the type of fire that will occur, the slight difference is irrelevant. Either type of alarm will detect nearly every type of fire quickly". ${ }^{24}$ Consumers or home safety/alarm distribution programs may, however, focus on cost. An alarm containing both technologies is more expensive; it may also be more likely rendered non-functional if either technology causes frequent nuisance alarms. Our results suggest that installing photoelectric smoke alarms on main floors of

\section{Key points}

- Among urban households in Washington state, ionization smoke alarms were more than twice as likely as photoelectric alarms to be non-functional 15 months after installation.

- The most common reasons for non-function were a disconnected or absent battery due to nuisance alarming.

- Photoelectric alarms may be preferred when a single alarm unit is selected by consumers or safety campaigns targeting similar populations.

- Designing smoke alarms that minimize nuisance alarming may result in longer term functionality.

homes similar to those in our study may increase the proportion of functioning alarms and therefore provide longer term protection.

Acknowledgements: We wish to thank the King County Fire Chiefs' Association for their support. We are also indebted to Ms Luann D'Ambrosio and Ms Milda Tautvydas for their organizational efforts, and to Mr Chris Mack for programming and data management assistance.

Funding: This work was supported in part by grant no. R49/CCR002570 from the Centers for Disease Control, with additional assistance from the King County Fire Chiefs' Association.

Competing interests: None.

\section{REFERENCES}

1. Mallonee S, Istre GR, Rosenberg M, et al. Surveillance and prevention of residentialfire injuries. N Engl J Med 1996;335:27-31.

2. Runyan CW, Bangdiwala SI, Linzer MA, et al. Risk factors for fatal residential fires. N Engl J Med 1992;327:859-63.

3. Ballesteros MF, Kresnow MJ. Prevalence of residential smoke alarms and fire escape plans in the US: results from the Second Injury Control and Risk Survey (ICARIS-2). Public Health Rep 2007;122:224-31.

4. Runyan CW, Johnson RM, Yang J, et al. Risk and protective factors for fires, burns, and carbon monoxide poisoning in U.S. households. Am J Prev Med 2005;28:102-8

5. Peek Asa C, Allareddy V, Yang J, et al. When one is not enough: prevalence and characteristics of homes not adequately protected by smoke alarms. Inj Prev 2005;11:364-8.

6. Smith CL. Fire incident study: National Smoke Detector Project. Bethesda, MD: US Consumer Product Safety Commission, January 1995

7. Ahrens M. U.S. experience with smoke alarms and other fire detection/alarm equipment. Quincy, MA: Fire Analysis and Research Division, National Fire Protection Association, November 2004

8. Shults RA, Sacks JJ, Briske LA, et al. Evaluation of three smoke detector promotion programs. Am J Prev Med 1998;15:165-71.

9. National Fire Protection Association. Fundamentals of fire alarm systems: definitions. In: Bunker MW Jr, Moore WD, eds. National fire alarm code handbook, NFPA 71. Quincy, MA: National Fire Protection Association, 1999:17-22.

10. Berger LR, Kuklinski DM. When smoke alarms are a nuisance: a call to action. Arch Pediatr Adolesc Med 2001;155:875-6.

11. Fazzini TM, Perkins R, Grossman D. Ionization and photoelectric smoke alarms in rural Alaskan homes. West J Med 2000;17:89-92.

12. Rowland D, DiGuiseppi C, Roberts I, et al. Prevalence of working smoke alarms in local authority inner city housing: randomized controlled trial. BMJ 2002;325:9981001.

13. DiGuiseppi C, Edwards $P$, Godward C, et al. Urban residential fire and flame injuries: a population-based study. Inj Prev 2000;6:250-4.

14. Istre GR, McCoy MA, Osborn $L$, et al. Deaths and injuries from house fires. N Engl J Med 2001;344:1911-6.

15. Thomas Guide King \& Snohomish Counties. Washington: Street Guide (King, Snohomish Counties Street Guide and Directory). Rand McNally \& Company, 2000.

16. US Fire Administration, Federal Emergency Management Agency. Protecting your family from fire. US Department of Commerce, Technology Administration, National Institute of Standards and Technology, Building and Fire Research Laboratory, RA 130, February 1993.

17. National Fire Protection Association. Fire warning equipment for dwelling units In: Bunker MW Jr, Moore WD, eds. National fire alarm code handbook, NFPA 71. Quincy, MA: National Fire Protection Association, 1999:303-18. 
18. McNutt LA, Wu C, Xue Xiaonan, et al. Estimating the relative risk in cohort studies and clinical trials of common outcomes. Am J Epidemiol 2003;157:940-3.

19. Roberts I. Smoke alarm use: prevalence and household predictors. Inj Prev 1996;2:263-5.

20. Harvey PA, Aitken M, Ryan GW, et al. Strategies to increase smoke alarm use in high-risk households. J Community Health 2004;29:375-85.

21. Satariano WA, Smith J, Swanson A, et al. A census-based design for the recruitment of a community sample of older adults: efficacy and costs. Ann Epidemiol 1998:8:278-82.
22. Bland SD. Injury prevention behaviors: a report card for the nation, 1995. Prev Med 1999;29:195-201.

23. Picavet HSJ. National health surveys by mail or home interview: effects on response. J Epidemiol Community Health 2001;55:408-13.

24. National Fire Protection Association, Research \& Reports. Fact sheet. Smoke alarms: make them work for your safety. http://www.nfpa.org/ categoryList.asp?categorylD = 278\&URL = Research\%208\%20Reports/ Safety\%20fact\%20sheets/Fire\%20protection\%20equipment/Smoke\%20alarms (accessed January 5, 2006).

\section{FUNDING AVAILABLE FOR RESEARCH PROJECTS}

The Committee on Publication Ethics (COPE) has established a Grant Scheme to fund research in the field of publication ethics. The Scheme is designed to provide financial support to any member of COPE for a defined research project that is in the broad area of the organisation's interests, and specifically in the area of ethical standards and practice in biomedical publishing. The project should have a specific goal and be intended to form the kernel of a future publication.

A maximum sum of $£ 5000$ will be allocated to any one project, but applications for smaller sums are welcomed.

The terms and conditions of the Grant are as follows:

- At least one of the applicants must be a member of COPE.

- Calls for applications will be made twice a year with closing dates of 1 December and 1 June. An electronic version of the application form must be sent to the Administrator no later than $12 \mathrm{pm}$ (noon GMT) on the closing date for consideration by COPE Council.

- The application must contain a lay summary of the project, a definition of the question to be posed, sufficient methodological detail to allow assessment of the viability of the project, a clear timeline and a definition of the likely deliverables. A full justification for the sum requested must accompany the application.

- A report on the progress of the research should be presented within one year of the award and at the end of the project. The grant must be used within two years from the date of award, and balance sheets must be forwarded annually. These should be sent to the Administrator. Any remaining funds after two years must be returned.

- It is anticipated that the work stemming from the project will be presented at one of COPE's annual seminar meetings within 2-3 years of the award. Such data may also be published in peer-reviewed journals. Any publications or related presentations at meetings by the recipient emanating in part or whole from COPE's support should be duly acknowledged and copies sent to the Administrator.

Applications are reviewed by a COPE sub-committee. Applicants will be advised of a decision as soon as practicable after the deadline date.

An application form can be obtained by contacting Linda Gough, COPE administrator, at LGough@ bmj.com or 0207383 6602. For more information on COPE, see http://www.publicationethics.org.uk/

The closing date for receipt of applications is 1 December 2007 or 1 June 2008. 